Pacific Journal of Mathematics

NON-APOSYNDESIS AND NONHEREDITARY 


\title{
NON-APOSYNDESIS AND NON-HEREDITARY DECOMPOSABILITY
}

\author{
H. E. SCHLAIS
}

Let $M$ be a compact metric continuum. If $x \in M$ let $K(x)$ be the set to which an element $y$ of $M$ belongs if and only if $M$ is not aposyndetic at $x$ with respect to $y$. If, for all $x$ in $M, x \in \operatorname{Int}(K(x))$, then $M$ is the union of a countable collection of indecomposable subcontinua each of which is the closure of an open set. There exists a compact metric continuum $M$ and a dense subset $J$ of $M$ such that for each $x \in J, K(x)=S$, but $M$ contains no indecomposable subcontinua with nonvoid interior. It is the case, however, that if $M$ has a point $x$ such that Int $(K(x))=\varnothing$ then $M$ contains an indecomposable subcontinua which intersects $\operatorname{Int}(K(x))$.

Professor F. Burton Jones, in [1], demonstrated that for compact metric continua relationships between nonaposyndesis and indecomposability exist. The examination of such relationships is continued in this paper. The primary concern is to show that certain nonaposyndetic properties, similar to but weaker than those of Theorems 9 and 10 of Jones' paper, insure the existence of indecomposable subcontinua.

1. Definitions. Let space be metric. For a set $A$, the interior of $A$ and the boundary of $A$ will be denoted by $\operatorname{Int}(A)$ and $\operatorname{Bd}(A)$ respectively. If $A$ and $B$ are sets, then by $A-B$ is meant $\{x \in A$ : $x \notin B\}$. The closure of $A$ will be denoted by $\bar{A}$. Given subsets $A$ and $B$ of a continuum $M, M$ is said to be aposyndetic at $A$ with respect to $B$ if there is a subcontinuum $H$ of $M$ such that $A \subset \operatorname{Int}(H) \subset H \subset$ $M-B$. For a subset $A$ of a continuum $M$ let $T_{M}(A)=\{x \in M: M$ is not aposyndetic at $\{x\}$ with respect to $A\}$ and $K_{M}(A)=\{x \in M: M$ is not aposyndetic at $A$ with respect to $\{x\}\} . T_{M}(x)$ and $K_{M}(x)$ will be used for $T_{M}(\{x\})$ and $K_{M I}(\{x\})$ and the subscript may be omitted where no confusion is likely to result (e.g. $\left.T_{M}(x)=T(x)\right)$.

2. Essentially indecomposable sets. Theorem 9 of [1] states that a necessary and sufficient condition that the continuum $M$ be indecomposable is that if $x$ and $y$ are points of $M$ then $M$ is nonaposyndetic at $x$ with respect to $y$. We obtain, from this condition, the following definition. A subset $A$ of a continuum $M$ is essentially indecomposable in $M$ (often, in context, essentially indecomposable) if whenever $x$ and $y$ are points of $A$ then $M$ is not aposyndetic at $x$ with respect to $y$. Thus the limit bar in the $\sin 1 / x$ continuum is 
essentially indecomposable in that continuum and any subset of an indecomposable continuum $S$ is essentially indecomposable in $S$.

The following is immediate from the definition.

THeorem 1. An essentially indecomposable open subset of a continuum $M$ is an essentially indecomposable subset of each subcontinuum of $M$ which contains it.

Lemma 1. If $A$ is an essentially indecomposable open subset of a compact continuum $M$ and $H$ is a subcontinuum of $M$ with $A-H=\varnothing$ then $A$ is contained in a component $C$ of $\overline{M-H}$.

Proof. Assume the lemma false. Then $\overline{M-H}$ is the union of disjoint closed sets $B_{1}$ and $B_{2}$. Assume, without loss of generality, that $B_{1}$ contains an open subset $U$ of $A$. Then if $x \in U$ and $y \in B_{2}, \cap A$, $H \cup B_{1}$ is a continuum with $x \in \operatorname{Int}\left(H \cup B_{1}\right) \subset H \cup B_{1} \subset M-y$. This is a contradiction.

If $F$ is a collection of sets then by $F^{*}$ is meant the union of the elements of $F$.

THEOREM 2. If $A$ is an essentially indecomposable open subset of a compact continuum $M$ and $F$ is a finite collection of subcontinua of $M$ such that for each $f \in F, A-f \neq \varnothing$, then $A$ is contained in one component of $\overline{M-F^{*}}$.

Proof. The theorem follows from Lemma 1 and Theorem 1 using finite induction.

THEOREM 3. If $A$ is an essentially indecomposable open subset of a continuum $M$, then there is an open subset $U$ of $M$, containing $A$, such that $U$ is maximal with respect to being essentially indecomposable and open. Further if $U \cap V \neq \varnothing$ with $V$ open and essentially indecomposable, then $V \subset U$.

Proof. Let $B=\{W \subset M: W$ is open, essentially indecomposable, and $W \supset A\}$. Let $U=B^{*}$. Clearly, a subcontinuum $K$ of $M$, containing a point of $U$ in its interior, contains $A$. Thus if $W \in B$, there is a point $x_{W}$ such that $x_{W} \in \operatorname{Int}(K)$; so $K \supset W$. Hence $U \subset K$ and $U$ is essentially indecomposable. If an essentially indecomposable open set $R$ contains $U$ then $R \supset A$ and $R \in B$; so $R \subset U$.

If $V$ is an essentially indecomposable open set such that $U \cap V \neq \varnothing$, then it follows that $U \cup V$ is essentially indecomposable and open. Thus $U \cup V \in B$ and so $V \subset U$. 
A subset $A$ of a continuum $M$ which is maximal with respect to being open and essentially indecomposable in $M$ will be called a maximal essentially indecomposable open subset of $M$.

COROLlary 3.1. There exist at most countably many maximal essentially indecomposable open subsets of a separable continuum $M$.

THEOREM 4. If an essentially indecomposable open subset $A$ of a compact continuum $M$ is such that $M-A$ has at most countably many components, then $\bar{A}$ is connected.

Proof. Assume the theorem false. Then there exists an essentially indecomposable open set $A$ with $\bar{A}=H \cup K$ where $H$ and $K$ are nonempty disjoint closed subsets of $M$ and $M-A$ has at most countably many components. Let $\left\{C_{i}: i=1,2, \cdots\right\}$ be a counting of the components of $M-A$. For $i=1,2, \cdots$, let $H_{i}$ be the collection of all components in $\bar{A}$ which contain a point of $C_{i}$ and let $K_{i}=\overline{C_{i} \cup H_{i}^{*} \text {. }}$ Since $A \subset \cup\left\{K_{i}\right\}$ there is a $j$ such that $K_{j}$ contains an open subset of $A$ and thus $K_{0}$ contains $A$. Let $A_{1}=\left\{h \in H_{j}: h \subset H\right\}$. Then $\overline{A_{1}^{*} \cup C_{j}}$ is a subcontinuum which contains an open subset of $A$ but does not contain $A$. This is a contradiction.

EXAMPLE 1. The closure of a maximal essentially indecomposable open set need not be connected. Let $M^{\prime}$ be a compact plane indecomposable continuum which contains the points $(0,0)$ and $(1,0)$. Let $M=\left\{(a, y, z):(x, y) \in M^{\prime}\right.$ and $z=0$ or $x>1 / 2$ and $\left.z=x-1 / 2\right\}$. Let $U$ be the open subset of $M$ which is $\{(x, y, z) \in M: x<1 / 2\}$. If $x$ and $y$ are points of $U$, it follows that $M$ is not aposyndetic at $x$ with respect to $y$ and $U$ is essentially indecomposable. If $V$ is an open subset of $M$ which properly contains $U$ then one of $A=\{(x, y, z) \in$ $M: x>1 / 2, z=0\}$ or $B=\{(x, y, z) \in M: x>1 / 2, z=x-1 / 2\}$ contains an open subset of $V$. Assume without loss of generality it is $A$. Then the subcontinuum of $M$ which is $M-A$ contains $U$ but does not contain $V$ and $V$ is essentially decomposable. Thus $U$ is a maximal essentially indecomposable open set. Clearly $\bar{U}$ is not connected.

Lemma 2. In a continuum $M$, if $y \in \operatorname{Int} K(x)$ then $K(y) \subset K(x)$ and, hence, Int $K(y) \subset \operatorname{Int} K(x)$.

For a continuum $M$, Int $I(M)$ denote $\left\{x \in M: x \in \operatorname{Int}\left(K_{M}(x)\right\}\right.$.

THEOREM 5. For a continuum $M, I(M)$ is an $F_{\sigma}$ set.

Proof. For each $\varepsilon>0$ let $I_{\varepsilon}=\{x \in I(M): d(x), M-\operatorname{Int}(K(x)) \geqq \varepsilon\}$. 
To see that $I_{\varepsilon}$ is a closed set let $p$ be a limit point of $I_{\varepsilon}$ and suppose $\left\{x_{i}: i=1,2, \cdots\right\}$ is a sequence of points of $I_{\varepsilon}$ which converges to $p$. There exists an integer $N$ such that if $i \geqq N$ and $j \geqq N$, then $d\left(x_{i}, x_{j}\right) \leqq \varepsilon / 2$. For such $i$ and $j \operatorname{Int}\left(K\left(x_{i}\right)\right)=\operatorname{Int}\left(K\left(x_{j}\right)\right)$ by Lemma 2. If $H$ is a subcontinuum of $M$ containing $p$ in its interior, then for some $i \geqq N$ the point $x_{i}$ is in $\operatorname{Int}(H)$ and therefore $\operatorname{Int}\left(K\left(x_{i}\right)\right) \subset H$. But Int $\left(K\left(x_{i}\right)\right)=\operatorname{Int}\left(K\left(x_{N}\right)\right)$, so Int $\left(K\left(x_{N}\right)\right) \subset K(p)$. Since $d\left(x_{N}, p\right) \leqq \varepsilon / 2$, $p \in \operatorname{Int}\left(K\left(x_{N}\right)\right)$ and $p \in I(M)$. If $x \in M$ is such that $d(x, p)<\varepsilon$ then there is an $e>0$ such that $d(x, p)+e<\varepsilon$. If $i>N$ is such that $d\left(x_{i}, p\right)<e$, then $d\left(x_{i}, x\right) \leqq d\left(x_{i} p\right)+d(x, p)<\varepsilon$ and $x \in \operatorname{Int}\left(K\left(x_{i}\right)\right)$. As above, $\operatorname{Int}\left(K\left(x_{i}\right)\right) \subset \operatorname{Int}(K(p))$ and so $d(p, S-\operatorname{Int} K(p)) \geqq \varepsilon$. Thus $p \in I_{\varepsilon}$.

Since $I(M)=\bigcup_{n=1}^{\infty} I_{1 / n}, I(M)$ is an $F_{\sigma}$ set

THEOREM 6. I $I(M)$ intersects an open subset $U$ of a complete continuum $M$ in a second category subset if and only if $U$ contains an essentially indecomposable open set.

Proof. If the open subset $U$ of $M$ contains a second category subset which is a subset of $I(M)$, then for some $M=1,2, \cdots$, the set $I_{1 / n}$ (as defined in the proof of Theorem 5) contains an open subset $V$. If $W$ is an open subset of $V$ of diameter less than $1 / 2 n$, then, for each $x \in W, K(x) \supset W$. Thus $W$ is essentially indecomposable.

Conversely, if the complete continuum $M$ contains an essentially indecomposable open set $U$, it then follows that for each $x \in U, x \in I(M)$.

COROLLARY 6.1. If, in the compact continuum $M, I(M)$ intersects the open subset $U$ of $M$ in a second category set, then $U$ intersects an indecomposable subcontinuum of $M$ which has a nonvoid interior.

Proof. From Theorem 6, $U$ contains an essentially indecomposable open subset of $M$. A subcontinuum of $M$ irreducible about $U$ is indecomposable.

COROLLARY 6.2. If $I(M)$ intersects each open subset of the compact continuum $M$ in a second category set then the collection of indecomposable subcontinua of $M$ which have nonvoid interior has a dense union in $M$.

EXAMPLE 2. A compact plane continuum $M$ in which $I(M)$ is dense which contains no indecomposable subcontinua with nonvoid interiors.

Let $D$ be the closed square disk in $E^{2}$ whose opposite vertices are $(-1,-1)$ and $(1,1)$. Let $D_{1}^{1}$ and $D_{1}^{2}$ be subsets of $D$ homeomorphic to $D-\{(1,0)\}$ which spiral out to $\mathrm{Bd}(D)$, as indicated in Figure 1, so that $\mathrm{Bd}(D)$ is the limiting set of each of the spirals. 


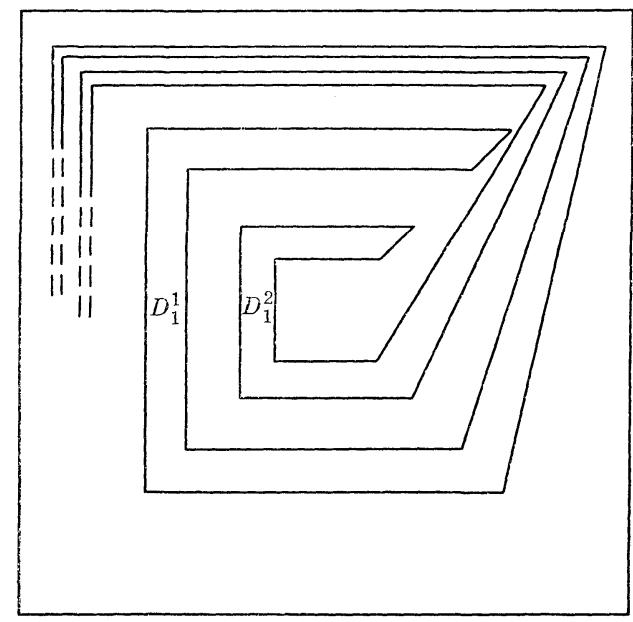

FIGURE 1

Define the spaces $M_{n}$ inductively as follows. Let $M_{1}=\overline{D_{1}^{1} \cup D_{1}^{2}}$. Let $f_{1}^{1}$ and $f_{1}^{2}$ be homeomorphisms of $D-\{(1,0)\}$ onto $D_{1}^{1}$ and $D_{1}^{2}$ respectively. Let $M_{2}=\overline{f_{1}^{1}\left(M_{1}-\{(1,0)\}\right)} \cup \overline{f_{1}^{2}\left(M_{1}-\{(1,0)\}\right)}$. For $n>2$, assume $M_{n-1}$ has been defined and let $D_{n-1}^{1}, D_{n-1}^{2}, \cdots, D_{n-1}^{2(n-1)}$ be a counting of the images in $M_{n-1}$ of $D_{1}^{1}$ and $D_{1}^{2}$ respectively. Let $f_{n-1}^{1}, f_{n-1}^{2}, \cdots, f_{n-1}^{2(n-1)}$ be homeomorphisms of $D-\{(1,0)\}$ onto

$$
D_{n-1}^{1}, D_{n-1}^{2}, \cdots, D_{n-1}^{2(n-1)} \text {, such that for each } x \in D-\{(1,0)\}
$$

$$
d\left(f_{n-1}^{j}(x), D-f_{n}^{j}\{D-\{1,0\}\}\right)<\frac{1}{n-1} .
$$

Let $M_{n}=\overline{\cup f_{n-1}^{j}\left(S_{1}-\{(1,0)\}\right)}, j=1,2, \cdots, 2^{(n-1)}$, and then define $M$ to be $\cap M_{n}, n=1,2, \cdots$.

If $n$ is a positive integer, $i \leqq 2^{n}$ and $p$ and $q$ are points in $\mathrm{Bd}\left(D_{n}^{i}\right)$, then it is clear that $M$ is not aposyndetic at $p$ with respect to $q$. Since, if $K \geqq n$ and $j \leqq 2^{K}$ is such that $D_{K}^{j} \subset D_{n}^{i}$, each point of $\operatorname{Bd}\left(D_{n}^{i}\right)$ is a boundary point of $D_{K}^{j}$, we have for each $x \in \mathrm{Bd}\left(D_{n}^{i}\right), K(x) \supset$ $\left\{\mathrm{Bd}\left(D_{k}^{j}\right): D_{k}^{j} \subset D_{n}^{i}\right\}^{*}$. It follows from (1) that, for such $x, K(x)$ is dense in $D_{n}^{i} \cap M$ and, since $K(x)$ is closed, it thus contains $\overline{D_{n}^{i}} \cap M$. If for some $n$ and $i, x \in \mathrm{Bd}\left(D_{n}^{i}\right)$ then $x \in \operatorname{Int}(K(x))$. Since, as above, $\left\{x: x \in \mathrm{Bd}\left(D_{n}^{i}\right), n=1,2, \cdots, i \leqq 2^{n}\right\}$ is dense, $I(M)$ is dense.

If $K$ is a subcontinuum of $M$ with interior, then there are integers $N$, $i$, and $j$, with $i \neq j$, such that $\operatorname{Int}(K) \cap D_{N}^{i} \neq \varnothing$ and $\operatorname{Int}(K) \cap$ $D_{N}^{j} \neq \varnothing$. The subcontinua $\overline{K \cap D_{N}^{i}}$ and $K \cap\left(M-D_{N}^{j}\right)$ of $K$ decompose $K$.

Lemma 3. Let $A$ be a maximal essentially indecomposable open 
subset of a compact continuum $M$ and $x \in I(M)$. Then if $x \notin \bar{A}, M$ is aposyndetic at $x$ with respect to $A$.

Proof. If $x \notin \bar{A}$ and $U$ is an open subset of $M-A$ such that $U \subset \operatorname{Int}(K(x))$, then $A \cup U$ is not essentially indecomposable. It follows from Lemma 1 that there is a subcontinuum $H$ of $M$ such that $H \supset A$ and $(A \cup U)-H \neq \varnothing-$ i.e., $M$ is aposyndetic at $A$ with respect to $U-H$. Since $U$ is any open subset of $\operatorname{Int}(K(x))-A$,

$$
B=\{y \in \operatorname{Int}(K(x)): T(y) \cap A=\varnothing\}
$$

is dense in $\operatorname{Int}(K(x))-A$. Let $K=\{T(y): y \in B\}^{*}$. Since $T(y)$ is connected [1, Theorem 3] and $x \in T(y)$ for each $y \in B, \bar{K}$ is a continuum. Since $x \notin \bar{A}, x \in \operatorname{Int}(\bar{K})$ and, since $\bar{K} \cap A=\varnothing$, we have the lemma.

Lemma 4. If, for a compact continuum $M, I(M)=M$ and $A$ is a maximal essentially indecomposable open set, then $\bar{A}$ is connected.

Proof. Assume, on the contrary, that $A$ is a maximal essentially indecomposable open set and yet $\bar{A}=A_{1} \cup A_{2}$ where $A_{1}$ and $A_{2}$ are separated subsets of $M$. Let $U$ be an open subset of $M-A_{2}$ containing $A$, with $\mathrm{Bd}(U) \cap \bar{A}=\varnothing$. By Lemma $3, M$ is aposyndetic at each $x \in \mathrm{Bd}(U)$ with respect to $A$. Hence there is a finite collection $\left\{H_{1}, H_{2}, \cdots, H_{n}\right\}$ of subcontinua whose interiors cover $\mathrm{Bd}(U)$ such that for each $i=1,2, \cdots, n, H_{i} \cap A=\varnothing$. By Theorem 2, there is a subcontinuum $C$ of $M$ with $C \subset \overline{M-\cup H_{i}}$ such that $A \subset C$. But then $C \subset M-\mathrm{Bd}(U)$ and so $\mathrm{Bd}(U)$ does not separate $M$ between $A_{1}$ and $A_{2}$. This is a contradiction.

THEOREM 7. If $M$ is a compact continuum with $I(M)=M$, then $M$ is the union of a countable collection of indecomposable continua each of which is the closure of a member of a closure preserving collection of maximal essentially indecomposable open subsets of $M$.

Proof. It follows from Theorem 6 and Corollary 3.1 that there is a countable collection of maximal essentially indecomposable open subsets of $M$ whose union is dense in $M$. Let $\left\{U_{n}: n=1,2,3, \cdots\right\}$ be a counting of this collection. Since for each $i, \bar{U}_{i}$ is connected (Lemma 4) it follows that $\bar{U}_{i}$ is an indecomposable continuum.

Let $U=\left\{U_{n_{i}}: i=1,2, \cdots\right\}$ be a subcollection of $\left\{U_{n}: n=1,2, \cdots\right\}$ and $x$ be an element of $M$ such that $x \notin \overline{U_{n_{i}}}$ for any $i$. Then, by Lemma 3, for each $i, M$ is aposyndetic at $x$ with respect to $U_{n_{i^{*}}}$ Thus $\operatorname{Int}(K(x)) \cap U_{n_{i}}=\varnothing$ for each $i$ and since $x \in \operatorname{Int}(K(x)), x \notin \overline{\cup U_{n_{i}}}$. Therefore $\left\{U_{n}: n=1,2, \cdots\right\}$ is closure preserving and $M=\cup \bar{U}_{i}$. 
EXAMPLE 3. There exists a compact metric continuum $M$ such that $I(M)=M$ and $M$ is not the union of the closures of any finite collection of maximal essentially indecomposable open sets.

For each $i=1,2, \cdots$ let $M_{i}$ be a planar indecomposable subcontinuum of $E^{3}$ of diameter less than $1 / i$ such if $i \neq j M_{i} \cap M_{j}=(0,0,0)$. Let $M=\cup M_{i}$.

Clearly $M=I(M)$. The maximal essentially indecomposable open subsets of $M$ are $\operatorname{Int}\left(M_{j}\right)$ relative to $M$. No finite collection of the closures of $\operatorname{Int}\left(M_{j}\right)$ has union $M$.

3. Non-aposyndesis and the existence of indecomposable subcontinua. An indecomposable subcontinuum $M$ is $K(x)$ for each $x \in M$ [1, Theorem 9], i.e., $M$ is $I(M)$. In Example 2, $I(M)$ is dense. Note also that if one takes a nested sequence $E$ of the $D_{n}^{i}$ 's used in the construction of Example 2, then the subspace $\bar{M}_{1}$ of $M$ (where $M_{1}$ is $\left.\cup\left\{D_{n}^{i} \cap M: D_{n}^{i} \in E\right\}\right)$ is an indecomposable continuum. This is seen by observing that if $x$ and $y$ are points of $\bar{M}_{1}$ then $\bar{M}_{1}$ is not aposyndetic at $x$ with respect to $y$ and applying Theorem 9 of [1] again. Since in each of the above examples there exists an indecomposable subcontinuum and $I(M)$ is infinite the following two considerations seem natural:

(a) If $I(M) \neq \varnothing$ then must it necessarily be infinite; and

(b) If $I(M) \neq \varnothing$ then must $M$ contain an indecomposable subcontinuum?

Consideration (a) is answered negatively by Example 4 while Theorem 9 shows that the answer to consideration (b) is yes.

EXAMPLE 4. There exists a compact plane continuum $M$ which has exactly one point $p$ such that $p \in \operatorname{Int}(K(p))$ (i.e., $I(M)=\{p\}$ ). For this point $K(p)=M$.

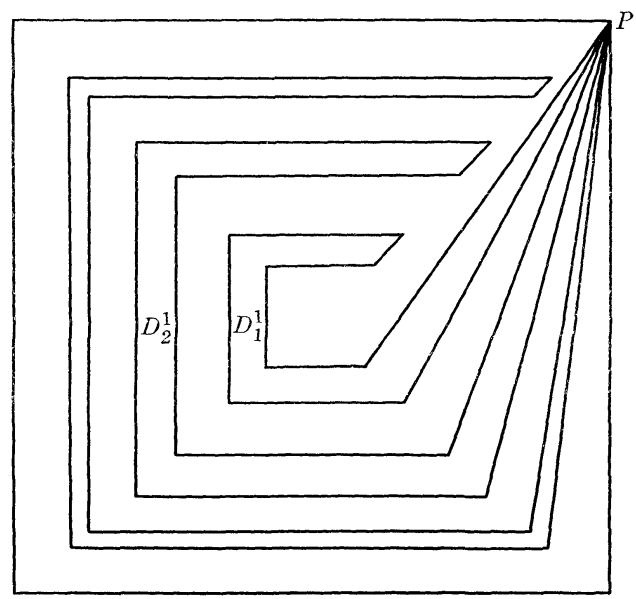

FIGURE 2 
Let $C$ be the unit square in the plane, $p \in C$, and, as indicated in Figure $2, D_{1}^{1}, D_{2}^{1}, \cdots$ be a sequence of closed topological disks in the plane having $C$ as its limit set, such that $D_{i} \cap D_{j}=\{p\}$ if $i \neq j$. Let $M_{1}=\left\{D_{i}^{1}: i=1,2, \cdots\right\} \cup C$. Assume $M_{n}$ to be defined and let $\left\{D_{i}^{n}: i=1,2 \cdots\right\}$ be a counting of the maximal topological disks in $M_{n}$. Let $f_{i}^{n}$ be a homeomorphism of $M_{1}$ into $D_{i}^{n}$ such that $f_{i}^{n}(p)=p, f_{i}^{n}(C)=$ $\operatorname{Bd}\left(D_{i}^{n}\right)$ and, for $x \in M_{1}$

$$
d\left(f_{i}^{n}(x), E_{2}-f_{i}^{n}(x)\right)<\frac{1}{n} .
$$

Let $M_{n+1}=\cup\left\{f_{i}^{n}\left(M_{1}\right): i=1,2,3, \cdots\right\}$ and $M=\cup\left\{M_{n}: n=1,2, \cdots\right\}$. If $C_{i}^{n}$ is the simple closed curve which is the boundary of $D_{i}^{n}$, then it is clear that for any $i$ and $n, M$ is not aposyndetic at $p$ with respect to any point of $C_{i}^{n}$. Thus

$$
K(p) \supset \cup\left\{C_{i}^{n}: n=1,2, \cdots, i=1,2, \cdots\right\} .
$$

It follows from condition (2) that $K(p)=M$. Clearly, if an element $x$ of $M$ is different from $p$ and $y \in K(x)$, there exists a sequence $\left\{y_{i}: i=1,2,3, \cdots\right\}$ converging to $y$ such that, for each $i, y_{i} \notin K(x)$. Thus $K(x)$ is nowhere dense for $x \neq p$ and $p$ is the only point of $M$ with $\operatorname{Int}(K(p)) \neq \varnothing$.

THEOREM 8. A necessary and sufficient condition that the compact continuum $M$ not be hereditarily decomposable is that, for some subcontinuum $K$ of $M$ and point $p$ of $K$, there exists a sequence $U_{1}, U_{2}, \cdots$, of pairwise disjoint open subsets of $M$ which converges to $p$ such that, for each $i, U_{i} \cap K \neq \varnothing, p \notin U_{i}$ and, if $i<j$, the p-component of $K-U_{i}$ does not intersect $\bar{U}_{j}$.

Proof. The sufficiency is established first. Assume $K, p$, and $U_{1}, U_{2}, \cdots$ are as in the statement of the theorem. Let $H$ be a subcontinuum of $K$ irreducible with respect to intersecting each $\bar{U}_{j}$. Assume $H$ is decomposable. Then $H=A \cup B$ where $A$ and $B$ are proper subcontinua of $H$. Assume without loss of generality $A \cap \bar{U}_{j} \neq \varnothing$ for infinitely many $j$. Then $p \in A$. It follows, that for each $i$ there is a $j>i$ such that $\bar{U}_{j} \cap A \neq \varnothing$. Hence for each $i, A \cap U_{i} \neq \varnothing$. But $A$ is a proper subcontinuum of $H$. This contradicts the choice of $H$.

To establish the necessity, let $K$ be an indecomposable subcontinuum of $M$ and $p \in K$. Let $U_{1}$ be an open set intersecting $K$ such that $p \notin \bar{U}_{1}$. Since $K$ is indecomposable, $p$ is not an interior point, relative to $K$, of $P_{1}$, the $p$-component of $K-U_{1}$. Thus there is an open set $U_{2}$ of diameter less than $1 / 2$, which intersects $K$, such that 


\section{$\bar{U}_{2} \cap P_{1}=\varnothing, d\left(p, U_{2}\right)<1 / 2$ and $\bar{U}_{2} \cap \bar{U}_{1} \neq \varnothing$.}

If the set $U_{n}$ has been defined, let $P_{n}$ be the $p$-component of $K-U_{n}$. Since $P_{n}=\cup\left\{P_{i}: i=1,2, \cdots, n\right\}$ contains no interior relative to $K, p$ is not an interior point, relative to $K$, of $P_{n}$. Let $U_{n+1}$ be an open set of diameter less that $1 /(n+1)$ which intersects $K$, such that $\overline{U_{n+1}} \cap P_{n}=\varnothing, d\left(p, U_{n+1}\right)<1 /(n+1)$ and $\overline{U_{n+1}} \cap \cup\left\{\bar{U}_{i}: i=\right.$ $1,2, \cdots, n\}=\varnothing$. Clearly $K, p$ and $U_{1}, U_{2}, \cdots$ are as required.

THeOREM 9. If $M$ is a compact continuum and for some $x \in M$, Int $(K(x)) \neq \varnothing$, then $M$ is not hereditarily decomposable.

Proof. Let $U_{0}$ be a nonempty open subset of Int $(K(x))$ with $\bar{U}_{0} \subset \operatorname{Int}(K(x))$ such that $x \notin \bar{U}_{0}$. Let $B$ be the set of points in $\bar{U}_{0}$ which are points of $C_{x}$, the $x$-component of $M-U_{0}$, and $U_{1}$ be an open subset of $U_{0}$ with $\bar{U}_{1} \subset U_{0}$. Let $\varepsilon_{1}$ be a positive real number less than $1 / 2$ such that $N_{\varepsilon_{1}}(B) \cap U_{1}=\varnothing$ and $N_{\varepsilon_{1}}(B) \subset \operatorname{Int}(K(x))$.

Since $M$ is not aposyndetic at $x$ with respect to any point of $U_{1}$, it can be seen as follows, that $C_{1}$, the $x$-component of $M-U_{1}$, does not contain $N_{s_{1}}(B)$. Assume the statement false. Since $C_{1}$ does not contain $U_{1}, x \in \overline{M-C_{1}}$. Clearly, $x$ is not in any component of $\overline{M-C_{1}}$ which intersects $U_{1}$. Thus for each $p \in U_{1}$, there exists mutually separated sets $A_{p}$ and $B_{p}$ such that $A_{p} \cup B_{p}=M-C_{1}, x \in A_{p}$ and $p \in B_{p}$. For $p \in U_{1}, C_{1} \cup A_{p}$ is a continuum. But $x \in \operatorname{Int}\left(C_{1} \cup A_{p}\right)$ and $C_{1} \cup A_{p} \subset M-\{p\}$. This is a contradiction. Let $U_{2}$ be a nonempty open subset of $N_{\varepsilon_{1}}(B)$ such that $\bar{U}_{2} \subset M-C_{1}$ and $\bar{U}_{2} \subset N_{\varepsilon_{1}}(B)-B$. Let $C_{2}$ be the $x$-component of $M-U_{2}$. Note, as follows, that $\operatorname{Int}\left(C_{2}\right)$ does not contain $B$. Assume that $B \subset \operatorname{Int}\left(C_{2}\right)$. Since $U_{2} \subset K(x)$, $\overline{x \in M-C_{2}}$. Further, $C$, the $x$-component of $\overline{M-C_{2}}$, does not intersect $U_{2}$ since $C \subset C_{1}$ and $U_{2} \cap C_{1}=\varnothing$. Thus there is a separation of $\overline{M-C_{2}}$ between $x$ and a point of $U_{2}$. As above, this is a contradiction.

If the set $U_{n}$ has been defined, let $C_{n}$ be the $x$-component of $M-U_{n}$ and $\varepsilon_{n}$ be a positive real number less than $1 / 2^{n}$ such that $N_{\varepsilon_{n}}(B) \cap\left(\bigcup_{i=1}^{n} U_{i}\right)=\varnothing$ and $N_{\varepsilon_{n}}(B) \subset \operatorname{Int}(K(x))$. It follows, as above, that $C_{n}$ does not contain $N_{s_{n}}(B)$. Let $U_{n+1}$ be an open subset of $N_{s_{n}}(B)$ such that $\overline{U_{n+1}} \cap C_{n}=\dot{\phi}$ and $\overline{U_{n+1}} \subset N_{\varepsilon_{n}}(B)-B$.

Assume without loss of generality that $U_{1}, U_{2}, \cdots$ converges to a point $b$ of $B$. Suppose $\bar{U}_{i} \cap C_{x} \neq \varnothing$ for some $i$. Since $\bar{U}_{1} \cap C_{x}=\varnothing$, there is a smallest $i>1$ such that $\bar{U}_{i} \cap C_{x} \neq \varnothing$. But then $\bar{U}_{i} \cap C_{i-1} \neq \varnothing$. This contradicts our choice of $U_{i}$. It now follows that $M, b$, and $U_{1}, U_{2}, \cdots$ satisfy the condition of Theorem 8 .

THEOREM 10. If an element $x$ of a compact continuum $M$ has Int $(K(x)) \neq \varnothing$ and $K$ is the collection of indecomposable subcontinua 
of $M$, then $K^{*}$ is dense in $\operatorname{Int}(K(x))$.

Proof. The choice for $U_{0}$ in the proof of Theorem 9 can be made in such a way that $U_{1}$ is any open subset of Int $(K(x))$ such that $x \notin \bar{U}_{1}$ and $\bar{U}_{1} \subset \operatorname{Int}(K(x))$. From the proof of Theorem 8, there exists an indecomposable subcontinuum at $M$ which intersects $U_{1}$. Since every open subset of Int $(K(x))$ contains such an open set, $K^{*}$ is dense in $\operatorname{Int}(K(x))$.

\section{REFERENCE}

1. F. B. Jones, Concerning non-aposyndetic continua, Amer. J. Math., 70 (1948), 403-413.

Received December 1, 1971.

The Virginia Military Institute 


\section{PACIFIC JOURNAL OF MATHEMATICS}

\section{EDITORS}

\author{
H. SAMELson \\ Stanford University \\ Stanford, California 94305 \\ C. R. HоввY \\ University of Washington \\ Seattle, Washington 98105
}

J. DugundJI

Department of Mathematics

University of Southern California

Los Angeles, California 90007

RICHARD ARENS

University of California

Los Angeles, California 90024

\section{ASSOCIATE EDITORS}
E. F. BeCKENBACH
B. H. NEUMANN
F. WOLF
K. YoshidA

\section{SUPPORTING INSTITUTIONS}

UNIVERSITY OF BRITISH COLUMBIA

CALIFORNIA INSTITUTE OF TECHNOLOGY

UNIVERSITY OF CALIFORNIA

MONTANA STATE UNIVERSITY

UNIVERSITY OF NEVADA

NEW MEXICO STATE UNIVERSITY

OREGON STATE UNIVERSITY

UNIVERSITY OF OREGON

OSAKA UNIVERSITY

\author{
UNIVERSITY OF SOUTHERN CALIFORNIA \\ STANFORD UNIVERSITY \\ UNIVERSITY OF TOKYO \\ UNIVERSITY OF UTAH \\ WASHINGTON STATE UNIVERSITY \\ UNIVERSITY OF WASHINGTON

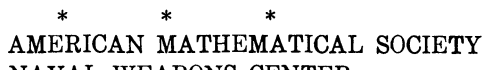 \\ NAVAL WEAPONS CENTER
}

The Supporting Institutions listed above contribute to the cost of publication of this Journal, but they are not owners or publishers and have no responsibility for its content or policies.

Mathematical papers intended for publication in the Pacific Journal of Mathematics should be in typed form or offset-reproduced, (not dittoed), double spaced with large margins. Underline Greek letters in red, German in green, and script in blue. The first paragraph or two must be capable of being used separately as a synopsis of the entire paper. The editorial "we" must not be used in the synopsis, and items of the bibliography should not be cited there unless absolutely necessary, in which case they must be identified by author and Journal, rather than by item number. Manuscripts, in duplicate if possible, may be sent to any one of the four editors. Please classify according to the scheme of Math. Rev. Index to Vol. 39. All other communications to the editors should be addressed to the managing editor, Richard Arens, University of California, Los Angeles, California, 90024.

50 reprints are provided free for each article; additional copies may be obtained at cost in multiples of 50 .

The Pacific Journal of Mathematics is issued monthly as of January 1966. Regular subscription rate: $\$ 48.00$ a year (6 Vols., 12 issues). Special rate: $\$ 24.00$ a year to individual members of supporting institutions.

Subscriptions, orders for back numbers, and changes of address should be sent to Pacific Journal of Mathematics, 103 Highland Boulevard, Berkeley, California, 94708.

PUBLISHED BY PACIFIC JOURNAL OF MATHEMATICS, A NON-PROFIT CORPORATION

Printed at Kokusai Bunken Insatsusha (International Academic Printing Co., Ltd.), 270, 3-chome Totsuka-cho, Shinjuku-ku, Tokyo 160, Japan. 


\section{Pacific Journal of Mathematics}

\section{Vol. 45, No. $2 \quad$ October, 1973}

Kenneth Paul Baclawski and Kenneth Kapp, Induced topologies for quasigroups and loops ............................................. 393

D. G. Bourgin, Fixed point and $\min -\max$ theorems $\ldots \ldots \ldots \ldots \ldots \ldots \ldots$

J. L. Brenner, Zolotarev's theorem on the Legendre symbol ............... 413

Jospeh Atkins Childress, Jr., Restricting isotopies of spheres .............. 415

John Edward Coury, Some results on lacunary Walsh series ................ 419

James B. Derr and N. P. Mukherjee, Generalized Sylow tower groups. II . . . . . . 427

Paul Frazier Duvall, Jr., Peter Fletcher and Robert Allen McCoy, Isotopy Galois

spaces .......................................... 435

Mary Rodriguez Embry, Strictly cyclic operator algebras on a Banach space ... 443

Abi (Abiadbollah) Fattahi, On generalizations of Sylow tower groups ......... 453

Burton I. Fein and Murray M. Schacher, Maximal subfields of tensor products . . 479

Ervin Fried and J. Sichler, Homomorphisms of commutative rings with unit

element .......................................... 485

Kenneth R. Goodearl, Essential products of nonsingular rings ............. 493

George Grätzer, Bjarni Jónsson and H. Lakser, The amalgamation property in

equational classes of modular lattices ...........................

507

$\mathrm{H}$. Groemer, On some mean values associated with a randomly selected simplex

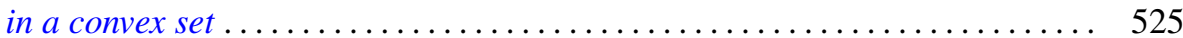

Marcel Herzog, Central 2-Sylow intersections .................... 535

Joel Saul Hillel, On the number of type-k translation-invariant groups ........ 539

Ronald Brian Kirk, A note on the Mackey topology for $\left(C^{b}(X)^{*}, C^{b}(X)\right) \ldots \ldots .543$

J. W. Lea, The peripherality of irreducible elements of lattice.............. 555

John Stewart Locker, Self-adjointness for multi-point differential operators ..... 561

Robert Patrick Martineau, Splitting of group representations ............... 571

Robert Massagli, On a new radical in a topological ring ................. 577

James Murdoch McPherson, Wild arcs in three-space. I. Families of Fox-Artin

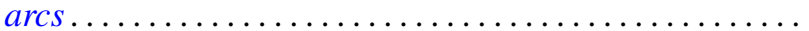

585

James Murdoch McPherson, Wild arcs in three-space. III. An invariant of

oriented local type for exceptional arcs . . . . . . . . . . . . ............ 599

Fred Richman, The constructive theory of countable abelian p-groups ........ 621

Edward Barry Saff and J. L. Walsh, On the convergence of rational functions

which interpolate in the roots of unity ..................

Harold Eugene Schlais, Non-aposyndesis and non-hereditary

decomposability..................................... 643

Mark Lawrence Teply, A class of divisible modules................... 653

Edward Joseph Tully, Jr., H-commutative semigroups in which each

homomorphism is uniquely determined by its kernel ................. 669

Garth William Warner, Jr., Zeta functions on the real general linear group ...... 681

Keith Yale, Cocyles with range $\{ \pm 1\} \ldots \ldots \ldots \ldots \ldots \ldots \ldots \ldots \ldots \ldots \ldots \ldots \ldots . \ldots \ldots$

Chi-Lin Yen, On the rest points of a nonlinear nonexpansive semigroup ........ 699 